\title{
A EDUCAÇÃO EMPREENDEDORA NO CONTEXTO DO ECOSSISTEMA EMPREENDEDOR DA UNIVERSIDADE FEDERAL DE SERGIPE
}

Gustavo Passos Fortes ${ }^{1}$

Diná Vieira De Matos ${ }^{2}$

\footnotetext{
${ }^{1}$ Universidade Federal do Sul e Sudeste do Pará
}

${ }^{2}$ Universidade Federal Rural da Amazônia 


\section{A EDUCAÇÃO EMPREENDEDORA NO CONTEXTO DO ECOSSISTEMA EMPREENDEDOR DA UNIVERSIDADE FEDERAL DE SERGIPE}

Resumo: Embora seja reconhecida a importância de se estabelecer um contexto de apoio ao empreendedorismo no ensino superior, ainda são poucos os estudos que abordam a importância da educação empreendedora para o ecossistema empreendedor na universidade. Neste contexto, é importante conhecer as ações de ensino, pesquisa e extensão relacionadas ao empreendedorismo no contexto da Universidade Federal de Sergipe (UFS). Este estudo objetivou mapear ações relacionadas à educação empreendedora na UFS, especificamente disciplinas ofertadas, projetos e pesquisas relacionadas à temática. A pesquisa se caracterizou como exploratório-descritiva, utilizando abordagem quantitativa de dados secundários, coletados em documentos e publicações oficiais da UFS e informações disponíveis no SIGAA (Sistema Integrado de Gestão de Atividades Acadêmicas). Os resultados mostraram que a UFS está iniciando o caminho como universidade empreendedora e que os grupos de pesquisa e os projetos que tratam de inovação são, em sua maioria, das áreas de ciências exatas e sociais aplicadas.

Palavras-chave: Ecossistema empreendedor. Educação empreendedora. Universidade empreendedora.

\section{$1 \quad$ Introdução}

O atual modelo de universidade amplia a missão de apenas produzir o conhecimento e pessoal qualificado, para o de contribuir com o desenvolvimento da região na qual está inserida. Nesse sentido, Teixeira, Santos e Fortes (2018) ressaltam a importância da educação empreendedora para impactar positivamente o contexto econômico. Tal educação empreendedora representa um papel importante da universidade que visa desenvolver o potencial empreendedor do aluno (DOLABELA; FILION, 2013) ao mesmo tempo em que influencia um processo de ensino-aprendizagem mais inovador no ensino superior (SCHAEFER; MINELLO, 2016).

Entende-se por ecossistema empreendedor o ambiente no qual a interação entre os atores que o compõe contribui para o seu desenvolvimento, influenciando a região geográfica que ocupam, seja ela um bairro, uma região, uma cidade ou um país (COHEN, 2006; ISENBERG, 2011). Segundo Lemos (2012), esta analogia de ecossistema empreendedor também se encaixa no contexto das universidades que interagem com elementos internos e externos, pelo fato das mesmas serem instituições nas quais a produção cientifica e tecnológica, a educação e a formação de pessoas são consideradas uma rotina de processos. Deste modo, faz-se necessária uma mudança de postura das universidades, uma vez que um de seus principais objetivos é o de transformar o conhecimento acadêmico em inovação, impactando a sociedade e gerando resultados econômicos e sociais (AUDY, 2017).

Henrique e Cunha (2008) destacam a dificuldade das universidades de formar o aluno para as reais necessidades da região e realidade das profissões. Assim, a universidade deve manter uma postura mais inovadora, seja nas metodologias de ensino ou projetos de pesquisa 
e extensão, no sentido de buscar atender essas necessidades da localidade (LEMOS, 2012; AUDY, 2017; DALMARCO; HULSINK; BLOIS, 2018). Nesse contexto, a educação empreendedora surge como uma alternativa inovadora de ensino que possibilita transformar a universidade em inovadora e atender ao retorno de investimento empregado (LIMA et. al., 2015; TEIXEIRA; SANTOS; FORTES, 2018).

O presente estudo tem o objetivo de analisar as ações relacionadas à educação empreendedora na Universidade Federal de Sergipe (UFS), mapeando as disciplinas relacionadas à educação empreendera ofertadas pela UFS; e Identificando os projetos de pesquisa e extensão que contribuem para a educação empreendedora e o ecossistema empreendedor na UFS.

\section{$2 \quad$ Referencial Teórico}

\subsection{Educação empreendedora}

De acordo com Druker (2017), os empreendedores são agentes que criam valor e transformam as oportunidades em algo concreto e valoroso para o desenvolvimento econômico. O empreendedorismo é o "fenômeno que ocupa papel de destaque na sociedade, esse fator reforça a importância de atividades empreendedoras em todos os contextos possíveis" (TEIXEIRA; SANTOS; FORTES, 2018, p. 142). As transformações do contexto atual exigem que a educação seja um mecanismo para desenvolver cidadãos críticos, inovadores e proativos (NECK; GREENE, 2011). Assim, o ensino do empreendedorismo deve quebrar um paradigma e ser encarado pelos educadores de forma transversal e não mais linear como o ensino tradicional (SCHAEFER; MINELLO, 2016).

Partindo da afirmação que as competências empreendedoras podem ser adquiridas por qualquer indivíduo (DORNELAS, 2017; SILVA; PENA, 2017), o ensino do empreendedorismo não deve ser encarado como um processo, visto que esse é previsível e o empreendedorismo não. Assim a educação empreendedora deve ser um arranjo abrangente de inúmeras e distintas abordagens de ensino e aprendizagem (SARASVATHY; VENKATARAMAN, 2011; NECK; GREENE, 2011).

As metodologias de ensino precisam ser construídas considerando a realidade histórica e os contextos contemporâneos que influenciam os processos educativos. Tais contextos são destacados pelas transformações econômicas, políticas, científicas e tecnológicas (LACANALLO et al., 2007; CARDOSO, 2017). Autores e pesquisadores da educação empreendedora consideram que a educação tradicional utiliza técnicas que limitam a criatividade dos alunos (SCHAEFER; MINELLO, 2016; KRAKAUER; SANTOS, ALMEIDA, 2016), fazendo com que a pedagogia da educação empreendedora seja focada no aluno e envolvendo a aprendizagem experiencial (SILVA; MANCEBO; MARIANO, 2017; ISMAIL, SAWANG E ZOLIN, 2018).

A educação empreendedora rompe com o modelo tradicional de ensino e traz uma proposta interdisciplinar, pautada em experiência de mercado do professor, consolidando a teoria e a prática ao desenvolver as competências empreendedoras (LIMA et al., 2014). A nova proposta da educação empreendedora não é mais ensinar o que é empreendedorismo, é ensinar a empreender (RIDEOUT; GRAY, 2013; SALUSSE; ANDREASSI, 2016). Para que isso ocorra, os professores devem adotar posturas empreendedoras, estar preparados para 
desenvolver metodologias especificas e cada vez mais inovadoras e inusitadas (RUSKOVAARA; HAMALAINEN; PIHKALA, 2016).

\subsection{Ecossistema empreendedor}

O conceito de ecossistema foi inicialmente aplicado à biologia, como o ambiente, não controlado, onde ocorre a interação de diversos atores em sobrevivência, evolução e desenvolvimento (OLIVEIRA, 2015). O autor afirma ainda que esse conceito está amplamente usado em outros segmentos e ciências, a exemplo do ecossistema de empreendedorismo que surgiu da analogia entre os ambientes biológicos e de negócios feita por Moore (1996).

O Ecossistema empreendedor pode ser conceituado e representado por um conjunto de agentes interagindo, em maior ou menor grau, em uma determinada região geográfica, que contribuem para o desenvolvimento do empreendedorismo (ISENBERG, 2011; COHEN, 2012;). Esses agentes que interagem no ecossistema empreendedor influenciam o desenvolvimento da região por meio da inovação e, quando analisados de forma conjunta passam a movimentar a dinâmica empreendedora com uma visão holística (MINEIRO et al., 2016; SILVA, 2017).

Oliveira (2015) e Mineiro et al. (2016) apresentam o ecossistema empreendedor vinculado à criação de startups. Contudo, este estudo tem como base o entendimento de Fetters et al. (2010), que trabalharam o ecossistema empreendedor de maneira mais abrangente, não apenas com o objetivo de criação de novas empresas. Para eles, as universidades contribuem ativamente no desenvolvimento do empreendedorismo por meio das forças econômica e social, as quais impulsionam ações de criatividade e inovação no ambiente acadêmico.

Com relação às ações inovadoras dentro da universidade, Bergmann et al. (2018) asseveram que o contexto de apoio ao empreendedorismo possibilita um clima de inovação e impulsiona o direcionamento de transferência de tecnologia para a comunidade. Porém, para que a universidade impacte diretamente o ecossistema empreendedor, é preciso incluir o clima empreendedor nas diretrizes estratégicas. Tais diretrizes provocam mudanças de postura do ambiente acadêmico e envolvem, diretamente, o gerenciamento de novas rotinas nas universidades e institutos de pesquisa, o qual deve estar articulado com a transferência de tecnologia, a gestão da propriedade intelectual, a integração da inovação e do empreendedorismo e, estrategicamente, à educação dos alunos, sendo necessários novos e diferentes recursos e habilidades (BENCKE et al., 2018; BERGMANN et al., 2018; FICHTER, K.; TIEMANN, 2018; PUGH, et al., 2018).

Assim, as universidades são elementos de importância central no ecossistema empreendedor de qualquer região, visto que são elas que formam os profissionais e produzem o conhecimento que será demandado pela comunidade (BERGMANN et al., 2018; PUGH et al., 2018). Portanto, o empreendedorismo no contexto das universidades deve transformar a mentalidade da comunidade acadêmica, possibilitando a criação de uma universidade empreendedora (FICHTER, K.; TIEMANN, 2018). 


\subsection{Universidade empreendedora}

O novo modelo de universidade relaciona-se ao conceito de universidade empreendedora que decorreu de uma série de mudanças denominadas revoluções acadêmicas (ETZKOWITZ; ZHOU, 2017) e que possibilitaram a evolução do perfil inovador das universidades (ETZKOWITZ, 2003), conforme mostra as Figuras 1 e 2.

\section{Figura 1 - Revoluções Acadêmicas}

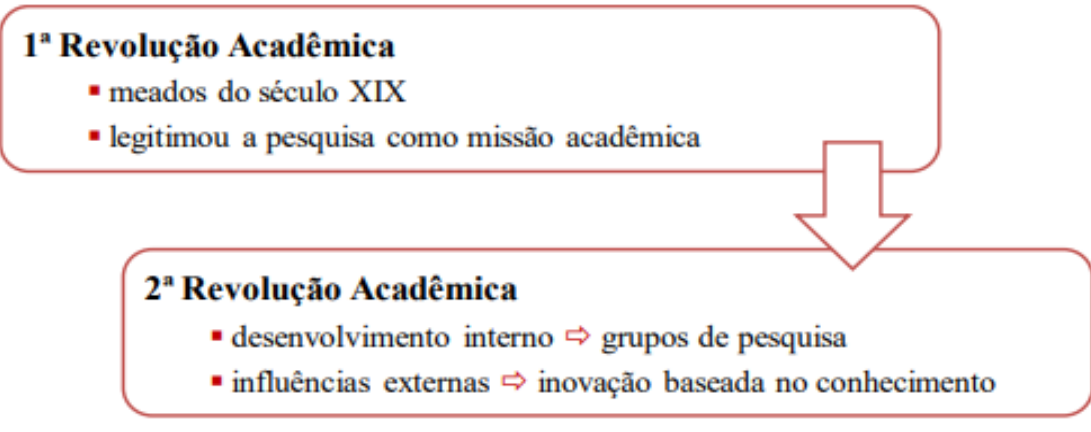

Fonte: Adaptado de Etzkowitz e Zhou, 2017.

Figura 2 - Evolução do Perfil Inovador das Universidades

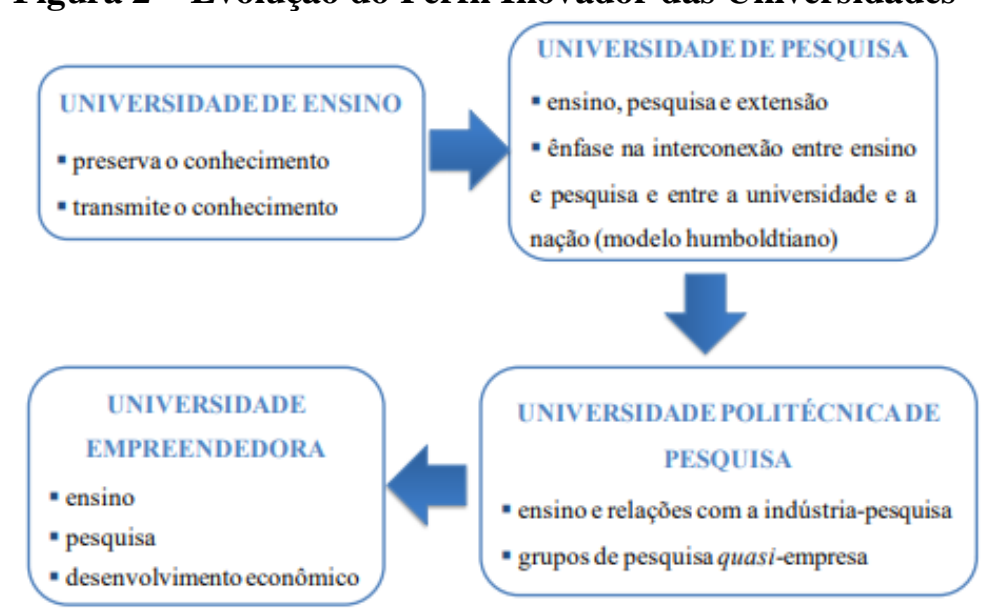

Fonte: Adaptado de Etzkowitz, 2003.

De acordo com Souza, Costa e Oliveira Júnior (2017), nas universidades tradicionais as pesquisas, as ações são desenvolvidas de acordo com a oferta dos profissionais envolvidos, a gestão é resistente aos processos de mudanças e não se trabalha com a previsão de riscos, possuindo receitas provenientes de políticas públicas. Por sua vez, as universidades empreendedoras atendem às demandas da sociedade, são abertas às mudanças, possuem uma gestão estratégica que prevê riscos, têm atitude proativa e trabalham com recursos financeiros diversificados.

Para Dalmarco, Hulsink e Blois (2018), a universidade visa oferecer cursos de empreendedorismo e inovação em todas as faculdades para melhorar a conscientização entre os alunos sobre como identificar novos mercados ou oportunidades. Além disso, Rasmussen e Borch (2010) afirmam que essa perspectiva empreendedora facilita a tomada de decisão dos 
alunos, fomentando o empreendedorismo universitário. Para Teixeira e Audy (2006), as experiências do MIT e das Universidades de Stanford e de Harvard impulsionaram o conceito de universidade empreendedora, alinhando o ensino e a pesquisa ao desenvolvimento econômico e social. A Universidade de Stanford, localizada no Vale do Silício, é uma das principais responsáveis pelo desenvolvimento da região e está envolta em uma relação direta com a comunidade na qual está inserida, uma vez que atende às demandas tecnológicas da região e as empresas disseminam os resultados de suas pesquisas por meio de relações de cooperação (ETZKOWITZ; ZHOU, 2017).

No Brasil, universidades como a USP e a UNICAMP conseguem a efetividade no processo de Transferência de Tecnologia (TT) utilizando-se dos seus escritórios, a Agência USP de Inovação e a Inova UNICAMP, respectivamente. Entre os anos de 2012 a 2014, a Inova UNICAMP assinou 31 contratos de licenciamento, 171 contratos em vigor, que juntamente com outras formas de TT, renderam um montante de mais de 2 milhões de reais.

\section{$3 \quad$ Metodologia}

O presente trabalho tem o objetivo de analisar as ações relacionadas à educação empreendedora na Universidade Federal de Sergipe, por meio das disciplinas ofertadas e projetos de pesquisa ou extensão. Creswell (2010) afirma que um estudo pode ser qualitativo, quantitativo ou misto e o pesquisador, de acordo com suas necessidades, escolhe o tipo de estudo que seja pertinente à pesquisa, podendo-se coletar os dados por meio de entrevistas, análises de documentos, dados audiovisuais e imagens. Assim, optou-se por utilizar a abordagem quantitativa, onde serão destacadas as ações relacionadas à educação empreendedora na universidade.

Quanto à estratégia de pesquisa, fez-se estudo de caso único, ou seja, uma investigação empírica que abrange planejamento, técnicas de coleta de dados e análise dos dados coletados (YIN, 2010). Foram utilizados somente dados secundários, coletados por meio de análise documental em documentos e publicações oficiais da UFS.

Buscando atender aos objetivos da pesquisa, a coleta de dados relacionada às disciplinas ofertadas pela UFS, foi realizada mês de junho de 2018. Buscou-se identificar os cursos de empreendedorismo ofertados, através do Sistema Integrado de Gestão de Atividades Acadêmicas da Universidade Federal de Sergipe (SIGAA/UFS), selecionando-se a aba "ensino" e, logo após, "componentes curriculares". Na busca "nome do componente" foram digitadas as palavras-chave empreendedorismo, iniciação empresarial, gestão de negócios, inovação e propriedade intelectual. Foram investigadas as disciplinas de empreendedorismo, inovação e propriedade intelectual ministradas na UFS, tanto na graduação quanto na pósgraduação, contabilizando-se apenas aquelas ativas no momento da consulta.

Os dados referentes ao segundo objetivo, relacionado aos projetos de pesquisa e extensão, foram coletados no mês de junho de 2018. Primeiramente, a pesquisa foi realizada no SIGAA/UFS, selecionando-se na aba "extensão" os projetos da UFS relacionados ao empreendedorismo que estão sendo desenvolvidos no âmbito da universidade.

Já com relação à pesquisa cientifica, buscando identificar os grupos de pesquisa atuantes na UFS, realizou-se, em junho de 2018, uma busca no diretório de grupos de pesquisa da plataforma do $\mathrm{CNPq}$, utilizando, na consulta parametrizada, a busca exata das palavras-chave inovação, empreendedorismo, propriedade intelectual, inovação tecnológica e 
transferência de tecnologia, aplicadas aos campos "nome do grupo", "nome da linha de pesquisa" e "palavra- chave da linha de pesquisa". Foram investigados grupos de pesquisa cadastrados na UFS, no Estado de Sergipe e na região Nordeste. É importante frisar que podem existir outros grupos de pesquisa que trabalham com estas temáticas. Todavia, os mesmos não utilizaram as palavras-chave no cadastro ou não atualizaram os dados; o contrário pode, também, ocorrer, em grupos que possuam as palavras-chave cadastradas, mas que não trabalham, necessariamente, nestas temáticas.

A coleta de dados referente aos projetos de pesquisa foi realizada através do SIGAA/UFS, selecionando-se a aba "pesquisa" e, logo após, "pesquisadores". No critério de busca foi selecionado o campo "objetivos", com a palavra-chave "inovação", e escolhido o centro. Não foi selecionada a opção ano, mas constam no SIGAA projetos entre os anos de 2012 e 2018.

\section{$4 \quad$ Resultados e discussões}

\subsection{Disciplinas de empreendedorismo ofertadas pela UFS}

De acordo com a pesquisa realizada, a Tabela 1 apresenta os dados referentes à graduação, a unidade responsável por ofertar a disciplina, o quantitativo de componentes curriculares e os cursos atendidos por cada área. As 27 disciplinas de Empreendedorismo/Gestão de Negócios/Iniciação Empresarial são ofertadas por 13 departamentos da instituição, para 21 cursos distintos, destacando-se o CCSA (Centro de Ciências Sociais e Aplicadas) e o CCET (Centro de Ciências Exatas e Tecnologia). Os componentes curriculares possuem nomenclaturas diferentes e algumas são direcionadas para o curso, a exemplo de Empreendedorismo na área ambiental, para o curso de Engenharia Ambiental e Sanitária, Tópicos Especiais em Empreendedorismo Rural, para Zootecnia, e Gestão de Negócios e Empreendedorismo Farmacêutico, para o curso de Farmácia. As disciplinas são obrigatórias apenas para 7 cursos, ou seja, 35\% dos cursos que a ofertam, sendo geralmente ofertadas entre os períodos $7^{\circ}$ e $11^{\circ}$ períodos de curso.

Ainda conforme a Tabela 1, as disciplinas de inovação são ofertadas por 6 departamentos, para 9 cursos distintos, entre o $7^{\circ}$ e o $10^{\circ}$ períodos, com destaque para o CCET. O Departamento de Engenharia de Produção ministra quase 50\% do total de disciplinas, para os cursos de Engenharia da Produção, Ciência da Computação, Engenharia da Computação e Engenharia Mecânica. Apenas no curso de Administração este componente curricular é obrigatório. Os componentes curriculares que tratam da Propriedade Intelectual são ofertados por 3 departamentos para 6 cursos distintos, para alunos entre o $6^{\circ}$ e o $10^{\circ}$ períodos. O departamento de Engenharia de Produção é responsável pela oferta de $75 \%$ das disciplinas com esta temática na UFS, ministrando para os cursos de Engenharia da Produção, Ciência da Computação, Engenharia da Computação e Engenharia Mecânica. Contudo, apenas 2 das 6 disciplinas ofertadas são obrigatórias. Os cursos de Direito e Relações Internacionais também abordam esta temática na sua grade, ainda que as disciplinas não sejam obrigatórias. 
Tabela 1 - Disciplinas ofertadas nas áreas de empreendedorismo e inovação por unidade responsável

\begin{tabular}{|c|c|c|c|c|c|c|c|}
\hline \multirow{2}{*}{ Centro } & \multirow{2}{*}{ Departamento/ /Núcleo } & \multicolumn{2}{|c|}{ Empreendedorismo } & \multicolumn{2}{|c|}{ Inovação } & \multicolumn{2}{|c|}{ Propriedade Intelectual } \\
\hline & & Disciplinas & Cursos & Disciplinas & Cursos & Disciplinas & Cursos \\
\hline $\mathrm{CECH}$ & Comunicação Social & 3 & 3 & - & - & - & - \\
\hline \multirow{4}{*}{ CCSA } & Administração & 9 & 8 & 1 & 1 & - & - \\
\hline & Turismo & 1 & 1 & - & - & - & - \\
\hline & Direito & - & - & - & & 1 & 1 \\
\hline & Relações Internacionais & - & - & - & & 1 & 1 \\
\hline \multirow{3}{*}{ CCAA } & Medicina Veterinária & 2 & 1 & - & - & - & - \\
\hline & Engenharia Agronômica & 1 & 1 & - & - & - & - \\
\hline & Zootecnia & 2 & 1 & - & - & - & - \\
\hline \multirow{7}{*}{ CCET } & Computação & 2 & 2 & - & - & - & - \\
\hline & Engenharia de Produção & 2 & 1 & 5 & 4 & 6 & 4 \\
\hline & Engenharia Ambiental & 1 & 1 & - & - & - & - \\
\hline & Tecnologia de Alimentos & 1 & 1 & - & - & - & - \\
\hline & $\begin{array}{l}\text { Núcleo de Graduação em } \\
\text { Engenharia de Petróleo }\end{array}$ & - & - & 1 & 1 & - & - \\
\hline & Engenharia Química & - & - & 1 & 1 & - & - \\
\hline & $\begin{array}{c}\text { Ciência e Engenharia de } \\
\text { Materiais }\end{array}$ & - & - & 1 & 1 & - & - \\
\hline \multirow{4}{*}{ CCBS } & Educação Física & 1 & 1 & - & - & - & - \\
\hline & Nutrição & 1 & 1 & - & - & - & - \\
\hline & Farmácia & 1 & 1 & 2 & 1 & - & - \\
\hline & TOTAL & 27 & & 11 & & 8 & \\
\hline
\end{tabular}

Fonte: Elaboração própria, 2018.

Apesar de Dalmarco, Hulsink e Blois (2018) ressaltarem que a oferta de disciplinas de empreendedorismo melhora a consciência sobre a identificação de oportunidades por parte dos alunos, cabe reforçar que não basta apenas oferecer as disciplinas de empreendedorismo, inovação e propriedade intelectual, devendo ser criado um ambiente que fomente o empreendedorismo e a inovação na universidade, no qual o perfil de alunos, professores, pesquisadores e todo corpo administrativo estejam alinhados. Ressalta-se também que as temáticas relativas à ciência da propriedade intelectual são diretas ou indiretamente debatidas nas disciplinas de Empreendedorismo, Inovação e Propriedade Intelectual.

\subsection{Projetos de extensão relacionados à educação empreendedora}

A Resolução no 53/2016/CONEPE define a Extensão Universitária como um princípio constitucional da indissociabilidade entre ensino, pesquisa e extensão, sendo "um processo interdisciplinar, educativo, cultural, científico e político que promove a interação transformadora entre Universidade e outros setores da sociedade", tendo a educação, saúde, comunicação, tecnologia e produção, meio ambiente, direitos humanos, cultura e trabalho como as áreas temáticas prioritárias.

Na UFS, as ações de extensão são geridas pela Pró-Reitoria de Extensão (PROEX) e demais órgãos vinculados a ela, e acontecem de cinco maneiras distintas: (1) projetos; (2) eventos; (3) cursos; (4) programas; e (5) serviços. Os projetos de extensão seguem as 
temáticas definidas pelo Plano Nacional de Extensão e envolvem atividades interdisciplinares de caráter eventual ou permanente, com o objetivo de integrar os trabalhos técnicos e científicos desenvolvidos junto à comunidade.

Com relação aos dados coletado na pesquisa, buscou-se identificar os projetos da UFS relacionados ao empreendedorismo que estão sendo desenvolvidos no âmbito da universidade. Sendo assim, dos 406 projetos de extensão, 19 trabalham a temática pesquisada (Quadro 1).

Quadro 1 - Projetos de extensão da UFS por unidade proponente

\begin{tabular}{|c|c|}
\hline Unidade Proponente & Nome do Projeto de Extensão \\
\hline Secretariado Executivo (DSE) & $\begin{array}{l}\text { UFS50- WEBSÉRIE: Empreendedorismo em São Cristóvão (2018) } \\
\text { UFS50 - Mensuração e Qualidade das Ações de Empreendedorismo da UFS (2018) } \\
\text { Empreendedorismo e Gestão de Pequenas Empresas Sergipana (2018) } \\
\text { UFS50 - E-books do Núcleo de Empreendedorismo (2018) } \\
\text { UFSPREF - Maratonas de Empreendedorismo e Inovação da UFS (2018) } \\
\text { Empreender UFS - Jogo: Caminhando Para Cidadania (2018) } \\
\text { UFSPM - Mentores Do Empreendedorismo (2018) } \\
\text { PD - Programa de Apoio e Orientação ao Trabalhador e Empreendedor (2018) } \\
\text { AVEX - Formação Empreendedora para Professores da UFS (2018) } \\
\text { Programa de Apoio e Orientação ao Trabalhador e Empreendedor (2017) }\end{array}$ \\
\hline $\begin{array}{l}\text { Departamento de Engenharia Química } \\
\text { (DEQ) }\end{array}$ & $\begin{array}{l}\text { UFS } 50 \text { - Impactos ambientais e sociais devido ao descarte incorreto dos efluentes da } \\
\text { carcinicultura versus o papel da comunidade acadêmica empreendedora (2018) }\end{array}$ \\
\hline Departamento de Química (DQI) & Empreender UFS - Economia Solidária na Ilha Mem de Sá (2018) \\
\hline $\begin{array}{l}\text { Coordenação de Tecnologias sociais e } \\
\text { Ambientais (CTSA) }\end{array}$ & Empreendedorismo e Tecnologias Sociais para o Desenvolvimento Sustentável (2018) \\
\hline Colégio de Aplicação (CODAP) & $\begin{array}{l}\text { * Professor Empreendedor: Ações Utilizando Materiais Manipuláveis numa Perspectiva } \\
\text { Inclusiva de Ensino-Aprendizagem de Matemática e Ciências (2018) }\end{array}$ \\
\hline $\begin{array}{l}\text { Campus Rural (CRU) - Departamento de } \\
\text { Engenharia Agronômica/UFS, } \\
\text { Departamento de Zootecnia/UFS }\end{array}$ & $\begin{array}{l}\text { Empreendedorismo em Assentamento Rural do Município de São Cristóvão a partir da } \\
\text { Proposta PAIS - Produção Agroecológica Integrada e Sustentável (2018) }\end{array}$ \\
\hline $\begin{array}{l}\text { Departamento de Ciências Contábeis } \\
\text { (DCC) }\end{array}$ & $\begin{array}{l}\text { EDUFIG - Educação fiscal e gerencial para se empreender frente às forças de mercado no } \\
\text { município de São Cristóvão (2018) }\end{array}$ \\
\hline $\begin{array}{l}\text { Departamento de Engenharia de } \\
\text { Produção (DEPRO) }\end{array}$ & Projeto Empreender Gamification (2018) \\
\hline $\begin{array}{l}\text { Departamento de Engenharia Elétrica } \\
\text { (DEL) }\end{array}$ & Fomentando a Educação Empreendedora no Rosa Elze (2018) \\
\hline $\begin{array}{l}\text { Departamento de Comunicação Social } \\
\text { (DCOS) }\end{array}$ & *estão e Pesquisa - Empreendedorismo e Marketing nas Mídias Sociais e Rádio UFS (2014) \\
\hline Departamento de Economia (DEE) & $\begin{array}{l}\text { Articulação Técnico-Econômica entre a Empresa Júnior de Economia (Mep Jr.) e os } \\
\text { Empreendimentos Solidários no Âmbito da Unitrabalho - Sergipe (2011) }\end{array}$ \\
\hline
\end{tabular}

Fonte: Elaboração própria, 2018.

As ações são criadas de acordo com demandas interdisciplinares, buscando desenvolver a comunidade, a exemplo da casa de extensão na Ilha Mem de Sá e da casa de extensão em Laranjeiras, além da proposta da casa de extensão no município de Brejo Grande, projetos que acontecem em parceria com associações de moradores e prefeituras dos municípios.

Outro dado coletado na pesquisa foi com relação à quantidade de projetos, eventos e cursos de extensão. Vale ressaltar que, nem toda ação de extensão é registrada no SIGAA ou institucionalizada e as informações cadastradas no SIGAA datam apenas de alguns anos, visto que a utilização mais efetiva do sistema pela extensão se deu apenas após 2016. A Tabela 2 apresenta e contabiliza as ações de extensão institucionalizadas e cadastradas no SIGAA, a partir do ano de 2011 até a data final dessa pesquisa. Apresenta, também, o quantitativo de projetos que se relacionam diretamente ao empreendedorismo e à inovação. 
Tabela 2 - Projetos, eventos e cursos de extensão da UFS

\begin{tabular}{cccc}
\hline Tipo de atividade & Quantitativo & Empreendedorismo e Inovação & $\begin{array}{c}\text { \% em relação ao tipo de } \\
\text { atividade }\end{array}$ \\
\hline Projetos de extensão & 406 & 19 & $5 \%$ \\
Eventos de extensão & 398 & 17 & $4 \%$ \\
Cursos de extensão & 275 & 24 & $9 \%$ \\
\hline TOTAL & $\mathbf{1 . 0 7 9}$ & $\mathbf{6 0}$ & $\mathbf{5 \%}$ \\
\hline
\end{tabular}

Fonte: Elaboração própria, 2018.

Somam-se 1079 atividades de extensão na UFS, das quais 38\% são relativas a projetos, $37 \%$ a eventos e o restante a cursos. Identificou-se, na pesquisa, 60 atividades voltadas diretamente ao empreendedorismo e para a inovação, apenas $5 \%$ das atividades totais de extensão.

\subsection{Pesquisa científica relacionada à universidade empreendedora}

Dalmarco, Hulsink e Blois (2018) sugerem avaliar nesta dimensão se a universidade possui uma estrutura bem estabelecida, com cursos e programas de pós-graduação, grupos e projetos de pesquisa, enfatizando que um dos aspectos-chave da transferência de tecnologia bem-sucedida é a qualidade da pesquisa realizada, com foco em inovação. A pesquisa acadêmica na universidade é "uma rotina dos processos de produção científica e tecnológica, educação e formação de pessoas, sobretudo em relação aos resultados da pós-graduação" (LEMOS, 2012, p. 21). Ainda segundo o autor, a Carnegie Foundation for the Advancement of Teaching considera como universidade de pesquisa a instituição que possui pelo menos 15 programas de doutorado e que forma ao menos 50 professores a cada ano.

A fim de complementar as informações e verificar se os grupos cadastrados no CNPq estão ativos, a pesquisa também foi realizada no SIGAA/UFS, em agosto de 2018, retornando 317 grupos de pesquisa, ou seja, 36 grupos podem não estar institucionalizados na UFS. O quantitativo dos grupos de pesquisa encontrados no CNPq para cada uma destas esferas e, também, o percentual de participação da UFS nos níveis regional e estadual é apresentado na Tabela 3.

Tabela 3 - Quantitativo de grupos de pesquisa no Nordeste, em Sergipe e na UFS

\begin{tabular}{cccccc}
\hline Grupos de pesquisa & Nordeste & Sergipe & UFS & UFS/Nordeste & UFS/Sergipe \\
\hline Total & 10.728 & 547 & 353 & $3,3 \%$ & $64,5 \%$ \\
Inovação & 524 & 43 & 23 & $53 \%$ & $3,4 \%$ \\
Empreendedorismo & 147 & 9 & 5 & $5 \%$ & $7,1 \%$ \\
Inovação tecnológica & 154 & 20 & 11 & $5,6 \%$ & $5,5 \%$ \\
Propriedade intelectual & 52 & 8 & 3 & $13,6 \%$ & $100 \%$ \\
Transferência de tecnologia & 22 & 3 & 3 & $5,0 \%$ \\
\hline
\end{tabular}

Fonte: Adaptado de http://lattes.cnpq.br/web/dgp, 2018.

Em relação ao Nordeste, os grupos da UFS que mais se destacam são os que tratam de transferência de tecnologia e propriedade intelectual. No contexto estadual, a universidade possui mais de $50 \%$ de participação em todas as áreas de estudo pesquisadas, ressaltando que todos os grupos de transferência de tecnologia do Estado são da instituição.

Um descritivo dos grupos de pesquisa da UFS é apresentado Quadro 2, onde é possível observar que um mesmo grupo de pesquisa pode atuar em diferentes áreas. 
Quadro 2 - Grupos de pesquisa da UFS que trabalham com inovação e empreendedorismo Área Grupo de pesquisa

\begin{tabular}{|c|c|}
\hline Área & Grupo de pesquisa \\
\hline \multirow{5}{*}{ Empreendedorismo } & 决 Marketing \\
\hline & 糔 Laboratório de Pesquisa em Empreendedorismo e Inovação - LEI \\
\hline & 㓥 Grupo de Pesquisa em Avaliação, Política, Gestão e Organização da Educação -APOGEU \\
\hline & 档 Empreendedorismo e Gestão de Pequenas Empresas Sergipanas \\
\hline & * Núcleo de Estudos Interdisciplinares da Gestão e Desenvolvimento Organizacional - NEIGDO \\
\hline \multirow{5}{*}{$\begin{array}{c}\text { Propriedade } \\
\text { intelectual }\end{array}$} & * Conservação, Melhoramento e Gestão de Recursos Genéticos - GENAPLANT \\
\hline & 决 Laboratório de Pesquisa do Desenvolvimento Cognitivo Humano - LADEC \\
\hline & * Grupo de Pesquisa em Estatística Aplicada \\
\hline & * Grupo de Pesquisa em Engenharia da Produção - GPEP \\
\hline & * Engenharia, Tecnologia e Ciência de Alimentos \\
\hline \multirow{11}{*}{ Inovação tecnológica } & * Qualidade e Desenvolvimento de Novos Produtos Alimentícios \\
\hline & 米 Laboratório de Pesquisa em Empreendedorismo e Inovação - LEI \\
\hline & 䊎 Integração de Processos Biotecnológicos \\
\hline & 粼 Grupo de Pesquisa em Estatística Aplicada \\
\hline & * Grupo de Pesquisa e Extensão em Funcionalidade Humana \\
\hline & * Grupo de Pesquisa em Engenharia da Produção - GPEP \\
\hline & * Grupo de Estudos e Pesquisas em Memória e Patrimônio Sergipano - GEMPS \\
\hline & 䊎 Engenharia, Tecnologia e Ciência de Alimentos \\
\hline & * Desenvolvimento de Tecnologia em Petróleo, Gás, Biocombustível e Energia \\
\hline & * Conservação, Melhoramento e Gestão de Recursos Genéticos - GENAPLANT \\
\hline & * Biotecnologia e Inovação Terapêutica \\
\hline \multirow{3}{*}{$\begin{array}{l}\text { Transferência de } \\
\text { tecnologia }\end{array}$} & * Desenvolvimento de Tecnologia em Petróleo, Gás, Biocombustível e Energia \\
\hline & * Engenharia, Tecnologia e Ciência de Alimentos \\
\hline & * Laboratório de Pesquisa do Desenvolvimento Cognitivo Humano - LADEC \\
\hline \multirow{7}{*}{$\begin{array}{l}\text { Outras áreas da } \\
\text { Inovação }\end{array}$} & * Grupo de Pesquisas Interdisciplinares em Secretariado - GPISEC \\
\hline & * Laboratório de Economia Aplicada e Desenvolvimento Regional - LEADER \\
\hline & 䊉 Laboratório de Estudos em Jornalismo \\
\hline & * Grupo de Pesquisa em Saúde e Inovação \\
\hline & * Laboratório para Universalização do Desenvolvimento, Inovação e Inteligência Computacional - Lüdiico \\
\hline & * Natureza Humana, Pluralismo e Multiculturalismo no Âmbito dos Direitos Humanos \\
\hline & 䊉 Observatório de Tecnologia, Inovação e Organizações - OTIO \\
\hline
\end{tabular}

Fonte: Adaptado de http://lattes.cnpq.br/web/dgp, 2018.

A partir das informações coletadas, elaborou-se a Figura 3 para representar as áreas pesquisadas no diretório e o quantitativo de grupos que retornaram na intersecção entre elas. Nota-se que aproximadamente $30 \%$, ou seja, 7 grupos possuem linhas de pesquisa voltadas para outras áreas da inovação, 39\% estão vinculados somente ao empreendedorismo ou à inovação tecnológica e $31 \%$ em pelo menos duas áreas concomitantemente.

Cabe destacar que nenhum dos grupos atua somente com a pesquisa sobre propriedade intelectual, temática estudada pelos grupos juntamente com a inovação tecnológica ou a transferência de tecnologia, não sendo observado grupo que pesquise a propriedade intelectual no contexto do empreendedorismo.

Por fim, o último item avalia os projetos de pesquisa relacionados diretamente à inovação. Essa análise através do Sistema Integrado de Gestão de Atividades Acadêmicas da Universidade Federal de Sergipe (SIGAA/UFS), buscando palavras chaves relacionadas à inovação. Como se pode notar nas Tabelas 4 e 5, o campus Lagarto não retornou resultados na busca.

A Tabela 4 apresenta a evolução do quantitativo de projetos por ano e por centro, onde se pode perceber que o ano de 2013 foi o que mais teve projetos de inovação desenvolvidos na UFS ( $22 \%$ do total), destacando-se o CCET, com 5 projetos. Em alguns centros pode-se 
notar a constância em manter projetos em funcionamento, como o CCSA, o CCBS e o CCET, já mencionado.

Figura 3 - Intersecção entre as áreas de pesquisa

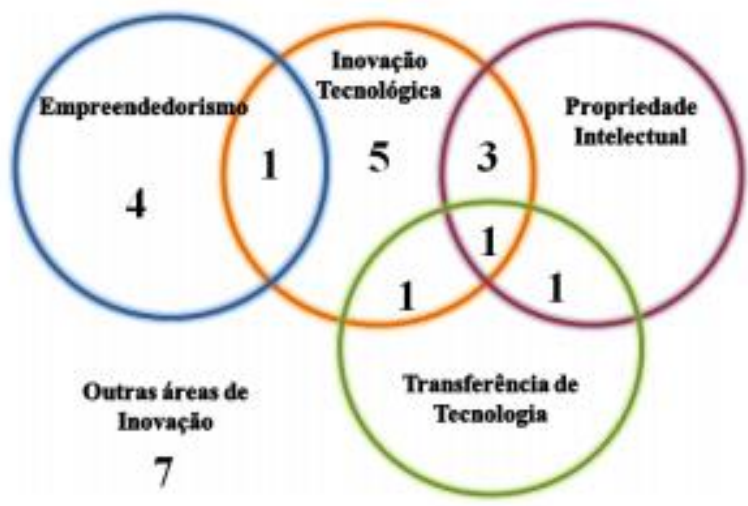

Fonte: Adaptado de http://lattes.cnpq.br/web/dgp, 2018.

Tabela 4 - Quantidade de projetos de inovação por ano e por centro

\begin{tabular}{cccccccc}
\hline Centro & \multicolumn{7}{c}{ Ano } \\
\cline { 2 - 8 } & $\mathbf{2 0 1 2}$ & $\mathbf{2 0 1 3}$ & $\mathbf{2 0 1 4}$ & $\mathbf{2 0 1 5}$ & $\mathbf{2 0 1 6}$ & $\mathbf{2 0 1 7}$ & $\mathbf{2 0 1 8}$ \\
\hline Campus de Lagarto & - & - & - & - & - & - & - \\
Campus de Laranjeiras & 1 & - & - & - & - & - & - \\
Campus do Sertão & - & - & - & - & - & 1 & - \\
Campus Itabaiana & - & - & 1 & - & 1 & - & - \\
CCSA & - & 5 & 3 & 4 & 3 & 1 & 1 \\
CCAA & - & - & - & 1 & 1 & 1 & - \\
CCBS & - & - & 1 & 2 & 2 & 2 & 2 \\
CCET & 5 & 10 & 5 & 5 & 6 & 7 & - \\
CECH & 1 & 2 & 1 & 1 & 1 & - & 12 \\
\hline TOTAL & $\mathbf{7}$ & 17 & 11 & 13 & 14 & & 3
\end{tabular}

Fonte: Elaboração própria, 2018.

No Quadro 3 estão os projetos de inovação separados por centro, em execução e finalizados, respectivamente. Alguns dos projetos foram contabilizados mais de uma vez, pois aparecem em anos e com códigos diferentes no SIGAA. Alguns, até no mesmo ano, como o projeto "Padronização de cerveja artesanal IPA com adjuvantes de interesse local por meio de leveduras nativas indígenas", do CCBS, que retornou 3 vezes na pesquisa, uma no ano de 2016 e duas em 2017, porém com códigos diferentes.

\section{Quadro 3 - Projetos de Inovação em Execução na UFS por centro}

\begin{tabular}{|c|c|}
\hline Centro & Nome do projeto de inovação \\
\hline Campus do Sertão & $\begin{array}{l}\text { - Desenvolvimento de queijo cottage saborizado como produto potencial para industrialização na bacia leiteira de } \\
\text { Sergipe (2017) }\end{array}$ \\
\hline CCSA & $\begin{array}{l}\text { - Processo de inovação em startups inseridas na rede “Caju Valley” em Sergipe (2018) } \\
\text { - Aplicativo para consultoria on-line (2018) }\end{array}$ \\
\hline CCAA & $\begin{array}{l}\text { - Formação de indicadores de ciência, tecnologia e inovação na indústria sergipana: identificando a relação entre } \\
\text { inovação e desenvolvimento socioeconômico (2017) }\end{array}$ \\
\hline
\end{tabular}


- Bioprospecção de fungos e leveduras endofíticos em Sergipe associado a sacatinga (croton argiphirodes: isolar, caracterizar e buscar inovação tecnológica) - (2017 e 2018)*

- Produção de cerveja artesanal pilsen por meio de leveduras nativas indígenas (2018)

- Padronização de cerveja artesanal IPA com adjuvantes de interesse local por meio de leveduras nativas indígenas $(2016 ; 2017 ; 2017)^{*}$

- Aplicação ex-situ de micro-organismos biorremediadores de ambientes antropizados com fins de interesse biotecnológico (2015)

- Microemulsão enriquecida com extrato clorofórmico de Schinus terebinthifolius Raddi potencialmente útil em processos inflamatórios (2015)

- Desenvolvimento por análise estatística em meios alternativos para obtenção de biossurfactante (2017)

- Mapeamento de inovação em startups e desenvolvimento de aplicativos (2017)

- Materiais cerâmicos avançados para componentes de sistemas construtivos (2017)

- Aplicação de cerâmicas porosas na geração de emissão laser aleatório (2017)

- SMART UFS.br: Smart CITy - Cidadania, Inovação e Transparência na difusão de ações e projetos de Cidades Inteligentes da UFS.br (2017)

- Estudo de análise de falhas, microestruturas e propriedades mecânicas de ligas industriais (2017)

- Gestão da qualidade e sua contribuição para inovação: uma perspectiva do pensamento sistêmico (2017)

- Síntese e determinação da estrutura molecular de derivados da isatina-tiossemicarbazona, uma classe de moléculas

CCET - Novas perspectivas na produção de Biossurfactantes (2016)

- Inovação em microestrutura e propriedades mecânicas de materiais para equipamentos da indústria de energia e mineração (2016)

- Conectando as ofertas de pesquisas de inovação da Universidade Federal de Sergipe com as demandas tecnológicas das empresas (2016)

- Nanocompósitos obtidos a partir de blendas de polietileno/poli (tereftalato de etileno) (2015)

- Desenvolvimento de ligas TiNbSn (2015)

- Inovação em materiais para equipamentos da indústria de energia e mineração (2015)

- Transferência tecnológica entre a Universidade Federal de Sergipe e Empresas (2015)

Analisando os títulos, alguns dos projetos estão diretamente relacionados à temática do empreendedorismo, consistindo em uma ação de educação empreendedora na universidade, como "Inovação em materiais para equipamentos da indústria de energia e mineração", "Mapeamento de inovação em startups e desenvolvimento de aplicativos", "Aplicativo para consultoria on-line", "Transferência de tecnologia entre a Universidade Federal de Sergipe e empresas", "Conectando as ofertas de pesquisas de inovação da Universidade Federal de Sergipe com as demandas tecnológicas das empresas", "Processo de inovação em startups inseridas na rede "Caju Valley" em Sergipe", dentre outros.

\section{Considerações finais}

O presente estudo teve o objetivo de identificar as ações relacionadas à educação empreendedora na UFS. Dessa forma foram mapeadas as disciplinas, projetos de pesquisa e de extensão da UFS que se relacionam à temática da educação empreendedora.

A primeira etapa do trabalho identificou as disciplinas relacionadas ao empreendedorismo e inovação ofertados na UFS. Assim, foi constatado que a consciência empreendedora, por meio das disciplinas ofertadas, pode ser incentivada em sala de aula em boa parte dos cursos da UFS. Porém ainda é preciso alinhar e aprimorar as metodologias de ensino-aprendizagem para que os alunos sejam impactados a fomentar negócios.

Com relação aos projetos de extensão, identificou-se que os projetos relacionados à educação empreendedora, na sua maioria, são incentivados a partir de demandas interdisciplinares promovidas pelas áreas de ciências exatas, tecnológicas e sociais aplicadas. Identificou-se ainda, que apenas $5 \%$ das ações de extensão da universidade são relacionadas à educação empreendedora. Tal realidade demonstra uma certa concentração de ações em 
determinadas áreas e a pouca disseminação do pensar empreendedor na extensão universitária da UFS como um todo.

Com relação à pesquisa cientifica que se relaciona de alguma forma com a educação empreendedora, constata-se que o quantitativo dos grupos de pesquisa da UFS é considerável, considerando o total da região Nordeste, Estado de Sergipe e na própria UFS. A temática da educação empreendedora que mais se discute nos grupos de pesquisas analisados é a questão inovação tecnológica. Essa realidade identifica que os grupos de pesquisa incentivam a educação empreendedora por meio de temáticas relacionadas e auxiliam a universidade a se tornar mais empreendedora.

\section{REFERÊECIAS}

ALMEIDA, M.; SANTOS, D.; ARAGÃO, L.; NOGUEIRA, G.; BONIFÁCIO, A.; SIMÕES, B.; TERRA, B. Expanding the vision of entrepreneurial universities: a case study of UNIRIO in Brazil. Triple Helix, v. 3, p. 1-19, 2016.

AUDY, J. A inovação, o desenvolvimento e o papel da Universidade. Estudos Avançados, v. 31, p. 75-87, 2017.

BENCKE, F. F., DORION, E. C. H., OLEA, P. M., PRODANOV, C. C., LAZZAROTTI, F., ROLDAN, L. B. A tríplice hélice e a construção de ambientes de inovação. Desenvolvimento em questão, v. 16, n. 43, abr./jun, p. 609-639. 2018.

BERGMANN, H.; GEISSLER, M. HUNDT, C.; GRAVE, B. The climate for entrepreneurship at higher education institutions. Research Policy. v. 47. n. 1, p.700-716, 2018.

CARDOSO, A., M. Educação empreendedora: métodos alternativos de ensino e aprendizagem para formação do empreendedor. Dissertação de Mestrado Faculdade Campo Limpo Paulista, SP: FACCAMP, 2017.

CAPES. Plataforma Sucupira - Coleta CAPES. Ministério da Educação. 2018. Disponível em: $<$ https://sucupira.capes.gov.br/sucupira/ >. Acesso em: 24 jun. 2018.

CNPQ. Diretório de grupos de pesquisa. Ministério da Ciência, Tecnologia e Inovação. 2018. Disponível em:< http://lattes.cnpq.br/web/dgp >. Acesso em: 24 jun. 2018.

COHEN, B. Sustainable Valley Entrepreneurial Ecosystem. Business Strategy and the Environment, v. 15, n. 1, p. 1-14, 2006.

COHEN, W. M., GOTO, A.; NAGATA, A.; NELSON, R. R.; WALSH, J. P. R\&D spillovers, patents and the incentives to innovate in Japan and the United States. Research Policy, v. 31, n. 8 , p. $1349-1367.2012$ 
CRESWELL, J. W. Projeto de pesquisa: método quantitativo, qualitativo e misto. 3.ed. Porto Alegre: Artmed, 2010.

DALMARCO, G.; HULSINK, W. ; BLOIS, G. V. . Creating entrepreneurial universities in an emerging economy: Evidence from Brazil. Technological Forecasting and Social Change, v. 135, n. 1 p. 99-111, 2018.

DORNELAS, J.C.A. Empreendedorismo: Transformando ideias em negócios. Rio de Janeiro: Elsevier, 2017.

DRUCKER, P. F. Inovação e espírito empreendedor: Práticas e princípios. Ed. ver. São Paulo, Cengage Learning, p. 400, 2017.

ETZKOWITZ, H. Research groups as 'quasi firms': the invention of the entrepreneurial university. Research Policy, n. 32, 2003.

ETZKOWITZ, H; ZHOU, C. Hélice tríplice: inovação e empreendedorismo universidadeindústria-governo. Estudos Avançados, v. 31 p. 23-48, 2017.

FETTERS, M. L; GREENE, P.; RICE, M. P.; BUTLER, J. S. The development of university-based entrepreneurship ecosystems - global practices. Cheltenham, Edward Elgar, 2010.

FICHTER, K.; TIEMANN, I. Factors influencing university support for sustainable entrepreneurship: insights from explorative case studies. Journal of Cleaner Production, v. 175 , p. 512-524, 2018.

ISENBERG, D. The Entrepreneurship Ecosystem Strategy as a New Paradigm for Economic Development: Principles for Cultivating Entrepreneurship. Babson Entrepreneurship Ecosystem Project. Babson College. 2011. Disponível em: http://entrepreneurial-evolution.com/2011/12/09/the-entrepreneurship-ecosystem-strategy-asa-new-paradigm-for-economic-development-principles-for-cultivating-entrepreneurship/. Acesso em 08 jun. 2018.

KRAKAUER, P. V. C.; SANTOS, S. A. D.; ALMEIDA, M. I. R. Teoria da Aprendizagem Experiencial no Ensino de Empreendedorismo: Um Estudo Exploratório. Revista de Empreendedorismo e Gestão de Pequenas Empresas, v. 6, n. 1, p. 101-127, 2017.

LACANALlO, L. F., SILVA, S., OLIVEIRA, D. E. M. B., GASPARIN, J., TERUYA, T. Métodos de ensino e de aprendizagem: uma análise histórica e educacional do trabalho didático. VII Jornada do Histedbr - O trabalho didático na história da educação. 2007.

LEMOS, P.A.B. Universidades e ecossistemas de empreendedorismo - a gestão orientada por ecossistemas e o empreendedorismo da Unicamp. Campinas: Unicamp, 2012. 
LIMA, E.; LOPES, R. M. A.; NASSIF, V. M. J.; SILVA, D. Oportunities to improve entrepreneurship education: contributions considering Brazilian Challenges. Journal of Small Business Management, v.53, n. 4, p. 1033- 105, 2015

NECK, H. M.; GREENE, P. G. Entrepreneurship education: known worlds and new frontiers. Journal of Small Business Management, v. 49, n. 1, p. 55-70, 2011.

MINEIRO, A.C; MIRANDA, P.B; OTTOBONI, C.; PASIN, L.M. Investigação do potencial de um polo de inovação para a criação de uma rede de investidores anjos a partir de seu ecossistema empreendedor. RACEF - Revista de Administração, Contabilidade e Economia da Fundace. v. 7, n. 1, p. 71-83, 2016.

MOORE, J.F. The death of competition: leadership and strategy in the age of business ecosystems. Harper Business New York, 1996.

OLIVEIRA, M. R. Modelo para o estímulo à criação de spin-offs acadêmicas baseado em ecossistemas empreendedores. 2015. Tese (Doutorado em Engenharia de Produção), Universidade Federal de São Carlos, São Carlos.

PUGH, R.; LAMINE, W.; JACK, S.; HAMILTON, E. The entrepreneurial university and the region: what role for entrepreneurship departments? European Planning Studies, v. 26, n. 9, p. 1835-1855, 2018.

RIDEOUT, E. C.; GRAY, D. O. Does entrepreneurship education really work? A review and methodological critique of the empirical literature on the effects of university-based entrepreneurship education. Journal of Small Business Management, v. 51, n. 3, p. 329351. 2013.

RUSKOVAARA, E.; HAMALAINEN, M.; PIHKALA, T. HEAD teachers managing entrepreneurship education e Empirical evidence from general education. Teaching and Teacher Education. v. 55, n. 1, p. 155-164, 2016.

SALUSSE, M. A. Y.; ANDREASSI, T. O Ensino de Empreendedorismo com Fundamento na Teoria Effectuation. Revista de administração contemporânea, v. 20, n. 3, p. 305-327, junho de 2016.

SANTOS, F. L. O Papel das ICT no desenvolvimento tecnológico do Brasil. In: SANTOS, F. L. (Org.). Desenvolvimento e Perspectivas da Propriedade Intelectual no Brasil. 1ed. Cruz das Almas: UFRB, 2014. p. 233-254.

SARASVATHY, S. D.; VENKATARAMAN, S. Entrepreneurship as method: Open questions for an entrepreneurial future. Entrepreneurship theory and practice, v. 35, n. 1, p. 113-135, 2011. 
SCHAEFER,R; MINELLO, I. F. Educação empreendedora: premissas, objetivos e metodologias. Pensamento contemporâneo em Administração. v. 10, n. 3, p. 60-81, 2016.

SILVA, F. C.; MANCEBO, R. C.; MARIANO, S. R. H. Educação Empreendedora como Método: O Caso do Minor em Empreendedorismo Inovação da UFF. REGEPE-Revista de Empreendedorismo e Gestão de Pequenas Empresas, v. 6, n. 1, p. 196-216, 2017.

SILVA, J. F.; PENA, R. P. M. O “Bê-Á-Bá” do Ensino em Empreendedorismo: Uma Revisão da Literatura sobre os Métodos e Práticas da Educação Empreendedora. Revista de Empreendedorismo e Gestão de Pequenas Empresas, v. 6, n. 2, p. 372-401, 2017.

SILVA, M.C. Análise do ecossistema empreendedor brasileiro e dos fatores críticos de sucesso para a gestão de incubadoras de empresa. 2017. 153f. Tese (Doutorado em Matérias e Processos de Fabricação) - Faculdade de Engenharia Mecânica, Universidade Estadual de Campinas, Campinas.

SOUZA, P. M.; COSTA, D. G.; OLIVEIRA JUNIOR, A. M. Entrepreneurial university: challenges and motivations of brazilian context. American International Journal of Contemporary Research, v. 7, p. 73-81, 2017.

TEIXEIRA, D. M.; SANTOS, J. M.; FORTES, G. P. Por uma sala de aula mais interessante! Senão for isso o que será? A educação empreendedora abrindo portas para o futuro da educação e da economia Revista Livre de Sustentabilidade e Empreendedorismo, v. 3, n. especial, p. 139-163, 2018.

TEIXEIRA, E.F.B.; AUDY, J. L. N. Universidade católica: entre a tradição e a renovação os desafios da construção de uma universidade empreendedora. (Org.) AUDY, J. L.N; MOROSINI, M. C.. Inovação e Empreendedorismo na Universidade. Porto Alegre: EDIPUCRS, v. 1, p. 442-461, 2006. 